\title{
A Clinical and Histopathological study of Lichenoid Eruption of Skin in Two Tertiary Care Hospitals of Dhaka.
}

\author{
Khaled A ${ }^{1}$, Banu SG ${ }^{2}$, Kamal $\mathrm{M}^{3}$, Manzoor ${ }^{4}$, Nasir TA ${ }^{5}$
}

\section{Introduction}

Skin diseases manifested by lichenoid eruption, is common in our country. Patients usually attend the skin disease clinic in advanced stage of disease because of improper treatment due to difficulties in differentiation of myriads of well established diseases which present as lichenoid eruption.

When we call a clinical eruption lichenoid, we usually mean it resembles lichen planus ${ }^{1}$, the prototype of this group of disease. The term lichenoid used clinically to describe a flat topped, shiny papular eruption resembling lichen planus. ${ }^{2}$ Histopathologically these diseases show lichenoid tissue reaction. The lichenoid tissue reaction is characterized by epidermal basal cell damage that is intimately associated with massive infiltration of $\mathrm{T}$ cells in upper dermis. ${ }^{3}$

The spectrum of clinical diseases related to lichenoid tissue reaction is wider and usually includes lichen planus, lichen planus like keratosis, lichen nitidus, lichen amyloidosis, lichenoid drug eruptions, lupus erythematosus, erythema multiforme, graft versus host disease, lichen striatus, keratosis lichenoides chronica and pityriasis lichenoides etc. ${ }^{4}$

Because of this heterogeneous assembly of clinical dermatosis, clinicopathologic correlation is essential in reaching a definite diagnosis. ${ }^{1}$

Routine histological examination with clinical and epidemiological information can help in the diagnosis of most of the lichenoid eruption. However, in some cases, axillary technique like immunofluroscence can define the disease more precisely. There are few studies in this country on lichenoid eruption both from clinical and pathological point of view and to compare with studies from other countries.

With this background, this present study was undertaken to know the clinical and histopathological pattern of lichenoid eruption, age and sex distribution of the diseases and to assess the clinical diagnostic accuracy by histopathology.

\section{Materials and Method}

A total of 134 cases were included in this study and these cases were collected from Bangabandhu Sheikh Mujib Medical University (Jan 2003 to Feb 2005) and Apollo Hospitals Dhaka (Oct 2006 to May 2008), both of these are large tertiary care hospitals in Dhaka. Biopsy specimen from patients of all age group having lichenoid eruption was included in this study. Detailed clinical history including age, sex, distribution of lesions, presence of itching, exacerbating factors, drug history, family history and any systemic manifestation were noted.

For routine examination, formalin fixed paraffin embedded tissue sections stained with haematoxylin and eosin were used.

For direct immunofluroscence examination, biopsy were collected in normal saline and after quick freezing, 4-5 $\mu \mathrm{m}$ sections were cut in cryotome. After washing in phosphate buffered saline, sections were incubated with FITC conjugated rabbit anti-human IgG, IgM, IgA, C3 and fibrinogen (DAKO). Then after glycerol mounting, the sections were examined for deposits under fluorescence microscope. All data were recorded meticulously as far as possible.

\section{Results}

A total of 134 cases were included in this study. 
Out of these 61 cases were male and 73 cases were female with a female to male ratio of 1.19:1. The age ranged from 2.5 years to 75 years with a mean age of 33.15 +- 16.75 years. For both male and female majority of the patients were in $2^{\text {nd }}$ and $3^{\text {rd }}$ decades of life (Fig 1)

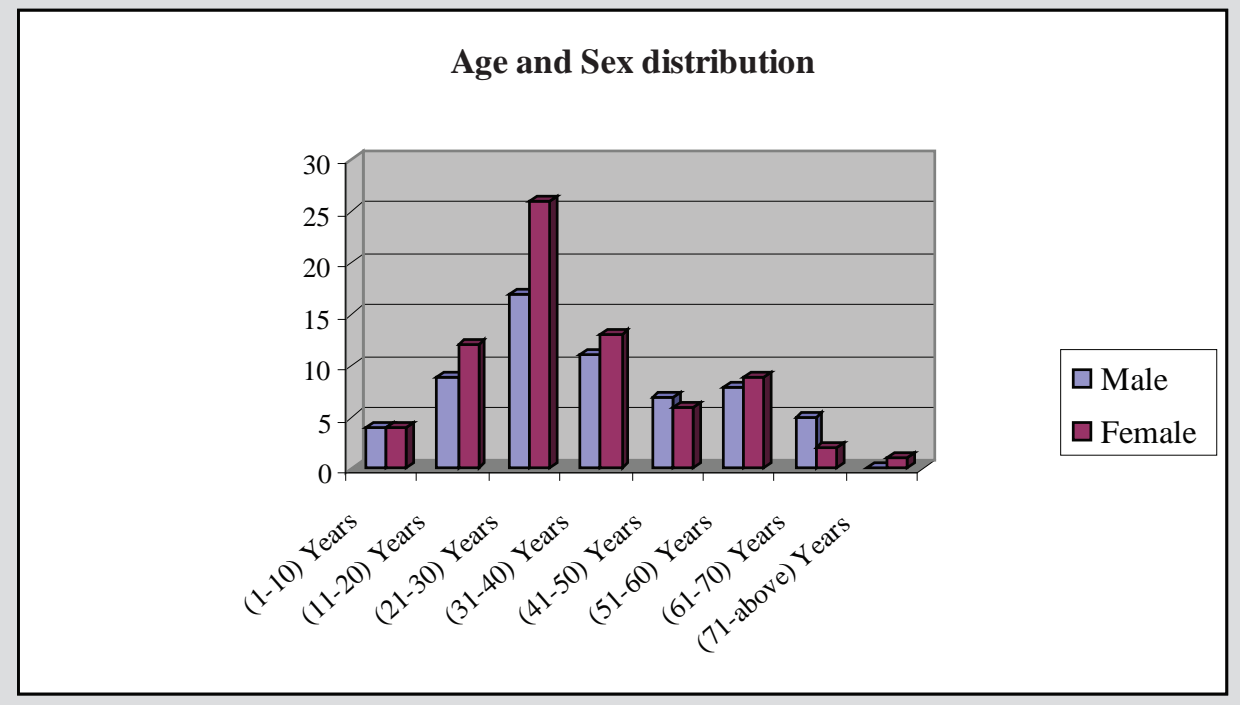

Figure 1: Age and sex distribution of the cases.

Detailed clinical history was obtained in all cases. Dermatologist made the clinical diagnosis on the basis of history and physical examination. Among the 134 cases, the most common clinical diagnosis was lichen planus 123 cases (91.79\%).
Other clinical diagnoses were discoid lupus erythematosus, lichenoid drug eruption, psoriasis and lichen simplex chronicus.

The distribution of clinical diagnosis of 134 cases of lichenoid eruption is shown in table1.

Table 1: Clinical Diagnosis of The Cases
\begin{tabular}{|l|l|l|}
\hline Clinical Diagnosis & No of Cases & $\%$ \\
\hline Lichen Planus (LP) & 123 & $91.79 \%$ \\
\hline Psoriasis (PSO) & 2 & $1.49 \%$ \\
\hline Lichen Simplex Chronicus (LSC) & 1 & $0.74 \%$ \\
\hline Discoid Lupus Erythematosus (DLE) & 6 & $4.47 \%$ \\
\hline Drug Eruption & 2 & $1.49 \%$ \\
\hline Total & 134 & \\
\hline
\end{tabular}

Histopathologically, lichen planus was also the commonest diagnosis, 88 cases (65.67\%). Other histopathological diagnosis were lichen simplex chronicus 18 cases, discoid lupus erythematosus 11 cases, lichenoid drug eruption 5 cases, lentigo simplex 2 cases, psoriasis 2 cases, lichen amyloidosis 1 case, pigmented purpuric dermatitis 1 case, lichen nitidus 1 case, chronic allergic dermatitis 1 case, subacute dermatitis 1 case and chronic non-specific dermatitis 2 cases. The distribution of histopathological diagnosis of 134 cases of lichenoid eruption is shown in table 2. 


\section{ORIGINAL ARTICLE}

Table 2: Histopathological diagnosis of the cases.

\begin{tabular}{|l|l|l|}
\hline Histopathological Diagnosis & No of Cases & $\mathbf{\%}$ \\
\hline Lichen Planus (LP) & 88 & $65.67 \%$ \\
\hline Chronic Non Specific Dermatitis (CND) & 2 & $1.49 \%$ \\
\hline Lichen Simplex Chronicus (LSC) & 18 & $13.43 \%$ \\
\hline Chronic Allergic Dermatitis (CAD) & 1 & $0.74 \%$ \\
\hline Lichen Nitidus & 1 & $0.74 \%$ \\
\hline Drug Eruption & 5 & $3.73 \%$ \\
\hline Discoid Lupus Erythematosus (DLE) & 11 & $8.20 \%$ \\
\hline Pigmented Purpuric Dermatitis (PPD) & 1 & $0.74 \%$ \\
\hline Lentigo Simplex (SAD) & 2 & $1.49 \%$ \\
\hline Psoriasis & 2 & $1.49 \%$ \\
\hline Sub Acute Dermatitis & 1 & $0.74 \%$ \\
\hline Lichen Amyloidosis & 1 & $0.74 \%$ \\
\hline Prurigo Nodularis & 1 & $0.74 \%$ \\
\hline Total & 134 & \\
\hline
\end{tabular}

Table 3: Correlation of clinical diagnosis with histopathological diagnosis of 134 case of lichenoid eruption.

\begin{tabular}{|c|c|c|c|c|c|c|c|c|c|c|c|c|c|c|}
\hline \multirow{2}{*}{$\begin{array}{l}\text { Clinical } \\
\text { Diagnosis }\end{array}$} & \multirow{2}{*}{$\begin{array}{l}\text { No of } \\
\text { Cases }\end{array}$} & \multicolumn{13}{|c|}{ Histopathological Diagnosis } \\
\hline & & L.P & $\begin{array}{l}\mathbf{C} \\
\mathbf{N} \\
\mathbf{D}\end{array}$ & $\begin{array}{l}\mathbf{L} \\
\mathbf{S} \\
\mathbf{C}\end{array}$ & $\begin{array}{l}\text { C } \\
\text { A } \\
\text { D }\end{array}$ & L. Nitidus. & Drug & $\begin{array}{l}\mathbf{D} \\
\mathbf{L} \\
\mathbf{E}\end{array}$ & $\begin{array}{l}\mathbf{P} \\
\mathbf{P} \\
\mathbf{D}\end{array}$ & Lsimplex & $\begin{array}{l}\mathbf{P} \\
\mathrm{S} \\
\mathbf{O}\end{array}$ & $\begin{array}{l}\text { S } \\
\text { A } \\
\text { D }\end{array}$ & L.Amyloidosis. & P.Nodularis \\
\hline Lichen Planus & 123 & 83 & 2 & 19 & 1 & 1 & 3 & 6 & 1 & 2 & 2 & 1 & 1 & 1 \\
\hline DLE & 6 & 1 & & & & & & 5 & & & & & & \\
\hline LSC & 1 & 1 & & & & & & & & & & & & \\
\hline Drug & 2 & & & & & & 2 & & & & & & & \\
\hline Psoriasis & 2 & 2 & & & & & & & & & & & & \\
\hline Total & 134 & 87 & 2 & 19 & 1 & 1 & 5 & 11 & 1 & 2 & 2 & 1 & 1 & 1 \\
\hline
\end{tabular}

The overall clinical diagnosis showed concordance with histologic diagnosis in $70.89 \%$ cases (Table 4 )

Table 4: Concordance and discordance between clinical diagnosis and histopathological diagnosis.

\begin{tabular}{|l|l|l|l|l|l|}
\hline Clinical Diagnosis & No of Cases & \multicolumn{5}{|c|}{ Histopathological Diagnosis } \\
\hline & & Concordance & \% & Discordance & \% \\
\hline Lichen Planus & 123 & 88 & $71.54 \%$ & 52 & $42.27 \%$ \\
\hline DLE & 6 & 5 & $83.33 \%$ & 1 & $16.66 \%$ \\
\hline Drug & 2 & 2 & $100 \%$ & 0 & - \\
\hline PSO & 2 & 0 & $0 \%$ & 2 & $100 \%$ \\
\hline LSC & 1 & 0 & $0 \%$ & 1 & $100 \%$ \\
\hline Total & 134 & 95 & $70.89 \%$ & 39 & $29.10 \%$ \\
\hline
\end{tabular}




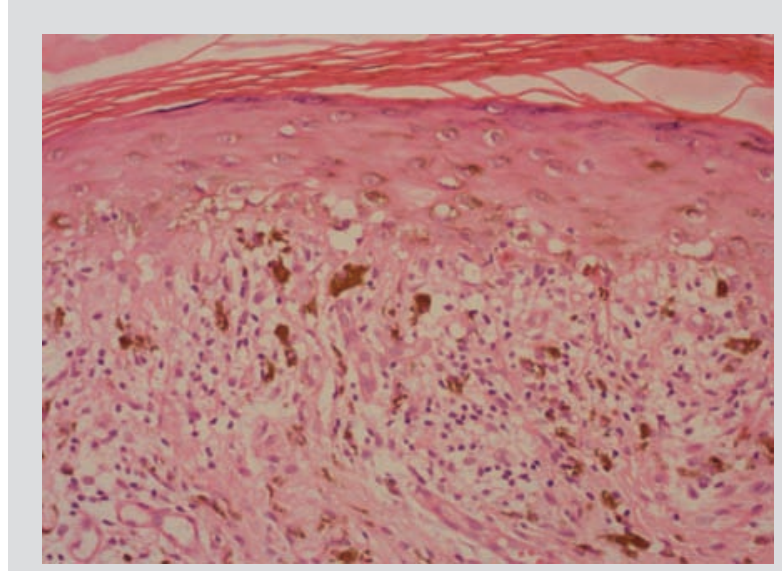

Fig 2a: Lichen planus showing typical lichenoid tissue reaction.

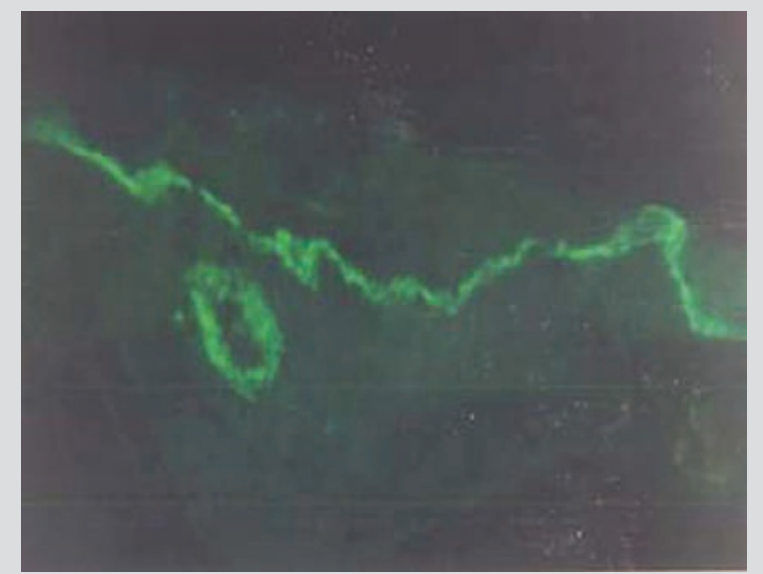

Fig 2b: Deposition of fibrin at the basement membrane zone in lichen planus

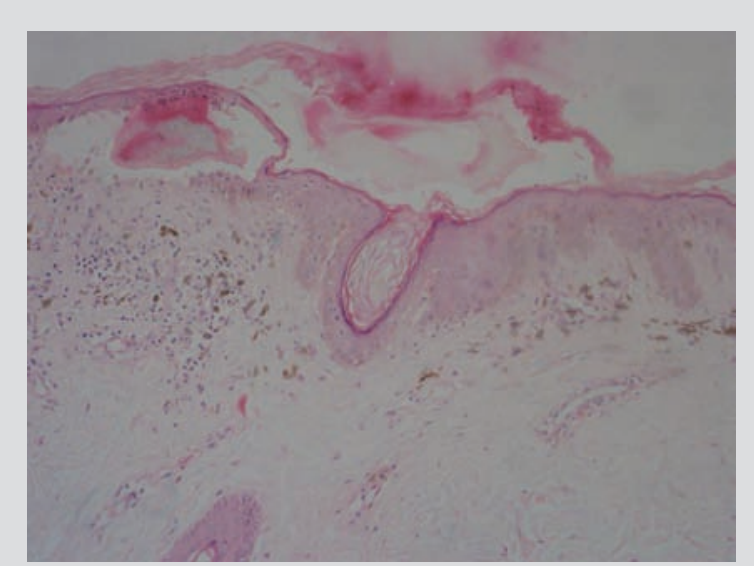

Fig 3a: Discoid lupus erythematosus showing thinning of epidermis, basal cell degeneration, follicular plugging and dermal odema

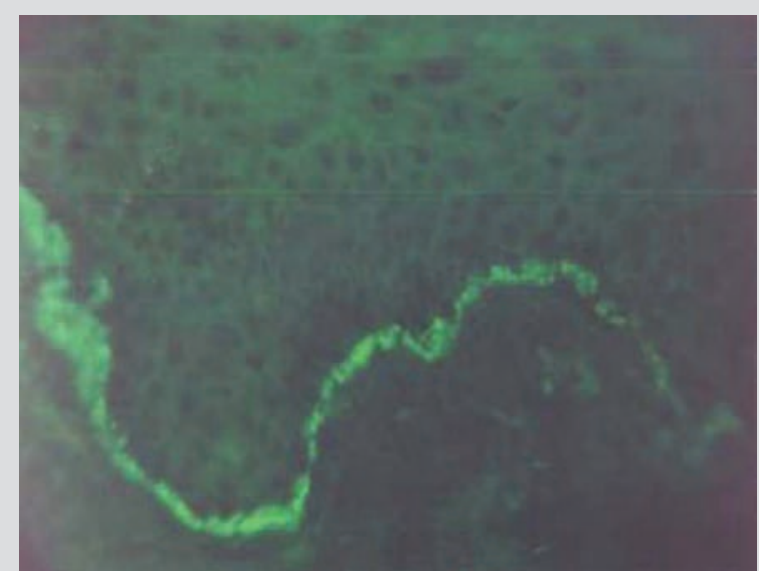

Fig 3b: Deposition of IgG at the basement membrane zone in discoid lupus erythematosus

Table 5: Result of direct immunofluroscence examination.

\begin{tabular}{|c|c|c|c|c|c|c|}
\hline \multirow[t]{3}{*}{ Clinical group } & \multicolumn{6}{|c|}{ No of patient } \\
\hline & \multirow[t]{2}{*}{ Total } & IgG & IgM & IgA & C3 & Fibrinogen \\
\hline & & $\begin{array}{ll}\mathrm{BM} & \mathrm{BV}\end{array}$ & BM $\quad$ BV & BM $\quad$ BV & BM $\quad$ BV & $\mathrm{BM}$ \\
\hline DLE & 5 & 5 & 3 & 1 & 4 & \\
\hline LP & 14 & & & & & 13 \\
\hline LSC & 5 & & 2 & & 1 & 2 \\
\hline
\end{tabular}

BM- Basement Membrane

BV- Blood Vessel 


\section{ORIGINAL ARTICLE}

\section{Duration of Lesions}

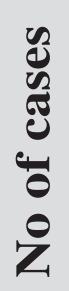

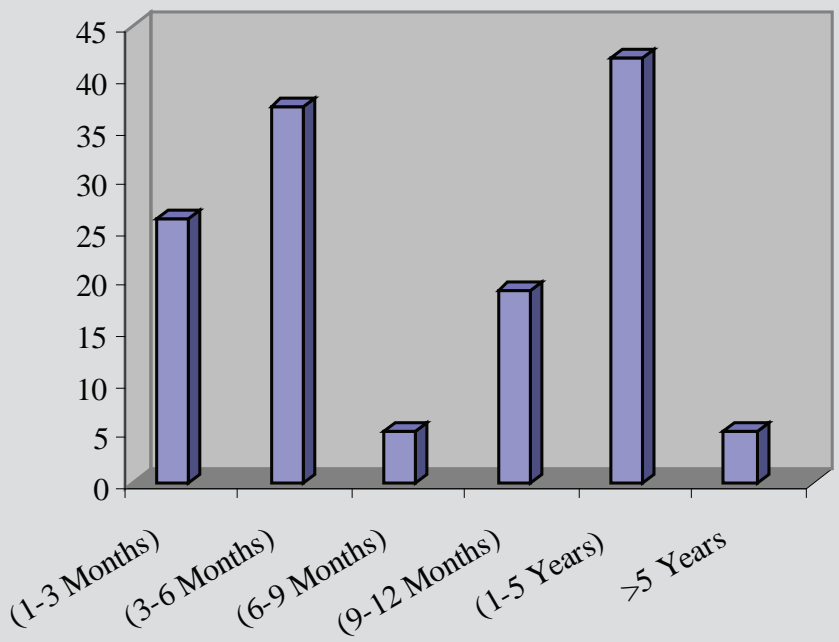

Duration

Figure 4: Duration of lesions of lichenoid eruption

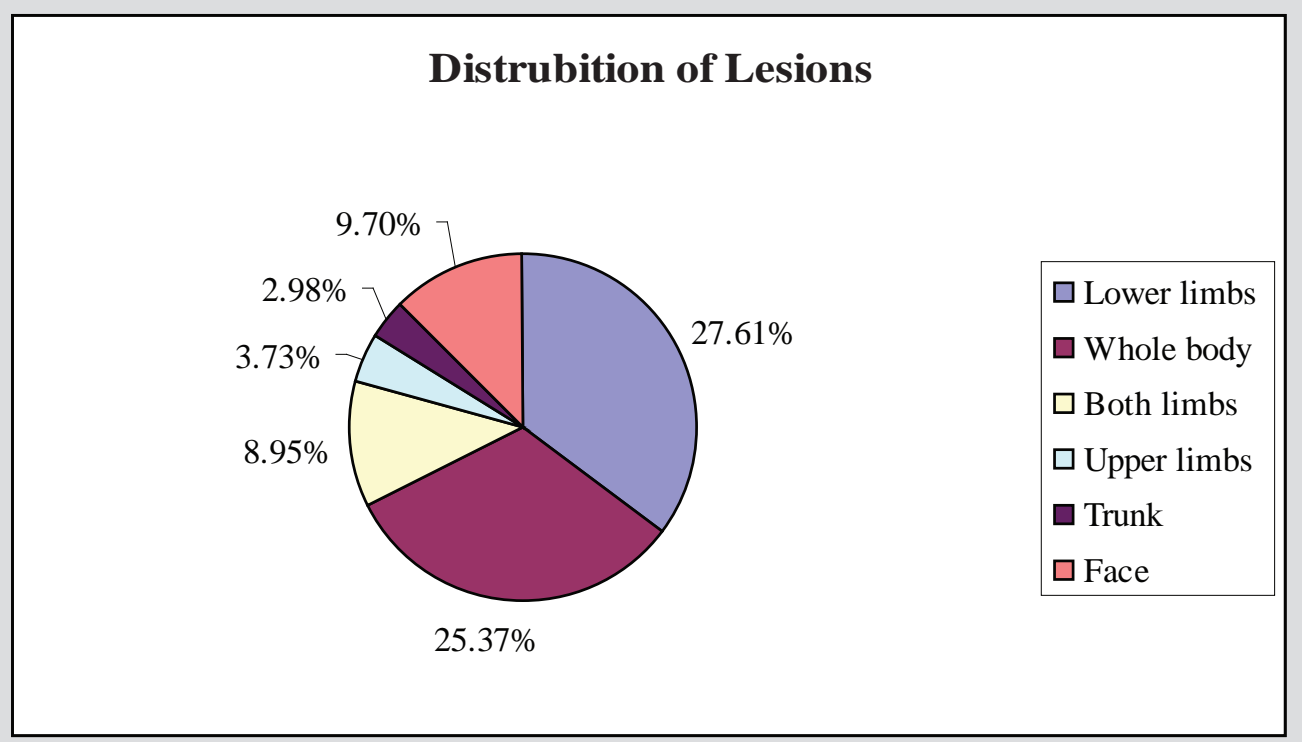

Figure 5: Distribution of lesions of lichenoid eruptions 
Severity of itching was assessed (Fig 6)

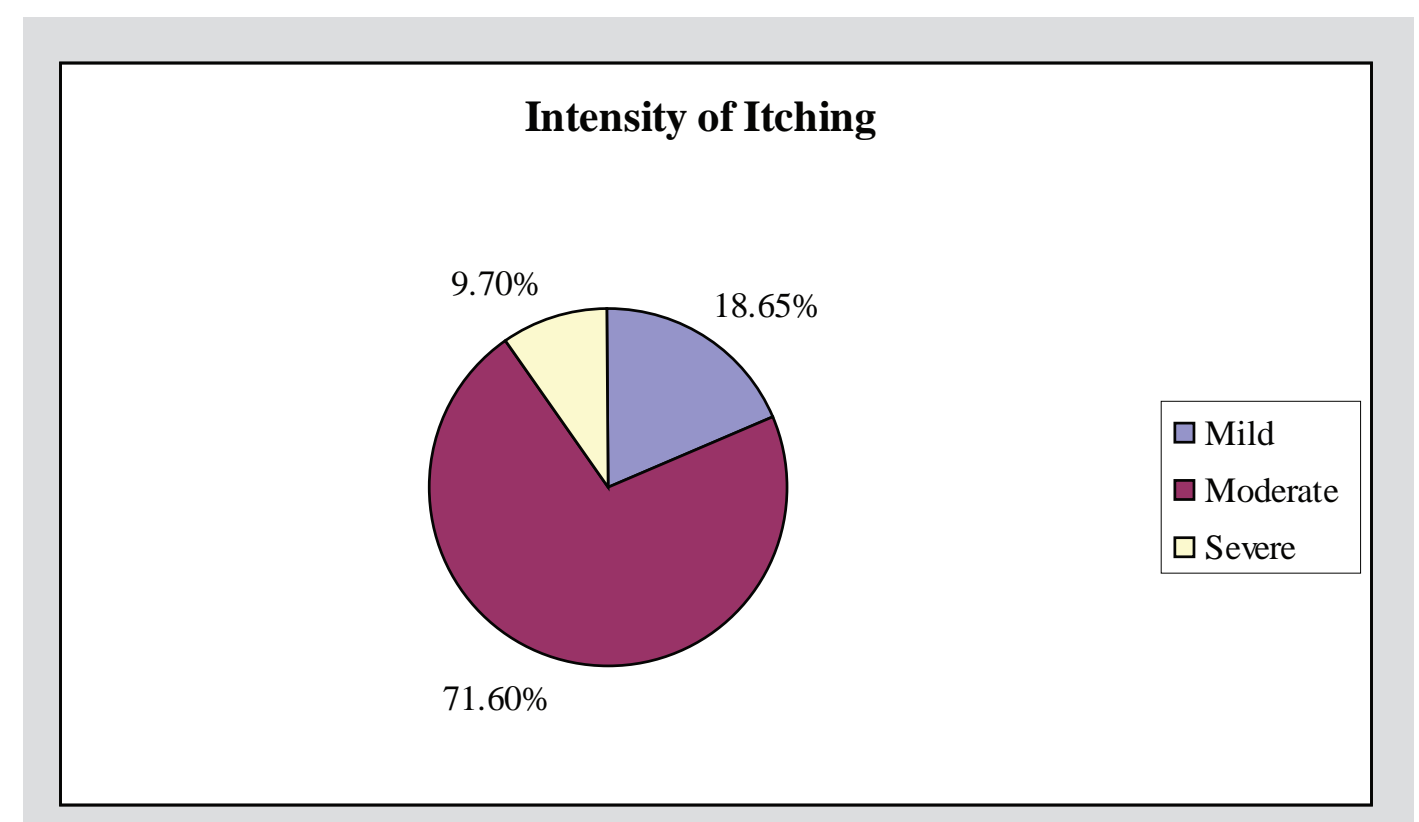

Figure 6: Severity of itching of the cases

\section{Discussion}

The present study was undertaken with the aim to demonstrate the disease pattern in patients who clinically present with lichenoid eruption of skin, age and sex distribution of the diseases and to assess the clinical diagnostic accuracy by histopathology.

For this purpose 134 cases were collected from two big hospitals of Dhaka city. In this study, cases as young as 2.5 years and as old as 75 years were observed indicating lichenoid lesion can occur at any age. Though maximum number of cases was found in $2^{\text {nd }}$ and $3^{\text {rd }}$ decades. The mean age of the subjects was $33.15 \pm 16.75$ years. Out of the 134 cases, 61 cases were male and 73 cases were female with female to male ratio of 1.19:1 indicating both being equally affected.

In this study, both limbs and trunk are commonly involved sites, with moderate itching and duration of 1 to 5 years in most of the cases. These findings are similar to other studies on lichenoid eruption. ${ }^{5-8}$
The overall clinical diagnosis showed concordance with histopathologic diagnosis in $70.89 \%$ cases with a positive predictive value of $67.47 \%$. Lichen planus was the commonest diagnosis both histologically and clinically. This indicates that clinicians are able to diagnosis the LP patient as LP and non-LP patient as non-LP efficiently. But most of the non-LP patients were over diagnosed as LP on clinical evaluation. These non-LP patients present with lichenoid eruption after histological examination diagnosed as other lichenoid dermatosis.

Other ancillary staining modalities like DIF can also help to diagnose these cases more accurately.

In conclusion, the present study reveals lichen planus is the commonest disease among lichenoid eruption, but many other lichenoid dermatosis may be diagnosed by routine histopathology and direct immunoflorescence study.

As the lichenoid eruption of skin consists of extremely heterogenous groups of diseases, clinical evaluation alone is not sufficient to 


\section{ORIGINAL ARTICLE}

reach a diagnosis. For this, histopathological examination is recommended for every case before treatment could be started.

\section{References:}

1. Mehregan AH. Pinkus' Guide to Dermatohistopathology, $4^{\text {th }}$ edition. Connecticut: Appleton-Century; 1986; p. 125-137, 395.

2. Black MM. Lichen planus and lichenoid disorders. In Champion RH, Burton JL, Ebling FJG, editors. Text book of Dermatology. $5^{\text {th }}$ edition, Vol-3. Oxford: Blackwell scientific publications; 1992; p.1675-1698.

3. T. Shiohara, Micukawa Y. The immunological basis of lichenoid tissue. Autoimmunity Reviews. 2005;236-241.
4. Elder D. Disorder of the superficial cutaneous reactive unit. Lever's Histopathology of the skin, 8th edition. Philadelphia: Lippincott Raven Publishers; 1997; p. 94.

5. Boyed AS, Neldner KH. Lichen planus. J Am Acad. Dermatol. 1991;25:593-619.

6. Anbar T, Barakat M, Ghannam SF. A clinical and epidemidogical study of lichen planus among Egyptians of A1-Minya Province. Dermatology online Journal. 2003;11(2):1-11.

7. Tilly JJ, Drolet BA, Esterly NB. Lichenoid eruptions in children. J Am Acad Dermastol. 2004;51(4):606-6245.

8. Singh OP, Kanwar AJ. Lichen planus in India. An Appraisal of 441 cases. Inter J Dermatol. 1976;15:752-756. 